\title{
Upaya untuk Meningkatkan Kemampuan Guru dalam Pemanfaatan Media Microsoft Powerpoint pada Mata Pelajaran SKI di MI NU Rawa Bening
}

\author{
Tri Ratna Dewi ${ }^{1}$, Nesi Anti Andini ${ }^{2}$ \& Miftakhur Rohmah ${ }^{3}$ \\ 1,2,3 STKIP Nurul Huda Sukaraja \\ E-mail: 1ratna@stkipnurulhuda.ac.id
}

\author{
INFO ARTIKEL ABSTRAK
}

\section{Available online}

URL:

https://journal.stkipnurulhuda.ac.id/ index.php/JIMi/article/view/444

\section{How to cite (APA):}

Dewi, T., Andini, N., \& Rohmah, M. (2019). Upaya untuk

Meningkatkan Kemampuan Guru dalam Pemanfaatan Media Microsoft Powerpoint pada Mata Pelajaran SKI di MI NU Rawa Bening. Jurnal Indonesia Mengabdi, 1(1), 30-33.

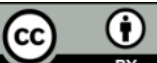

This work is licensed under a Creative Commons Attribution 4.0 International License

\begin{abstract}
Abstrak
Guru merupakan penggerak pendidikan, di era digital guru dituntut untuk memperbaharui pembelajaran dengan memanfaatkan teknologi yang ada dengan tujuan agar tidak tertinggal dengan perkembangan zaman. Fakta dilapangan menunjukan kondisi yang memprihatinkan, pemanfaatan teknologi masih belum maksimal. Hal tersebut disebabkan karena kurangnya fasilitas yang menjadi penunjang berkembangnya teknologi pembelajaran dan juga sumber daya manusia yang menguasai teknologipun tergolong minim. Pembinaan ini bertujuan untuk memberikan pelatihan dengan menyajikan beberapa materi yang berkaitan dengan pengembangan media pembelajaran yang interaktif yakni Media Microsoft Power Point agar pelaksanaan pembelajaran SKI pada sekolah MI Rawabening terkesan tidak monoton sehingga mampu meningkatkan minat serta kualitas pembelajaran di kalangan siswa. Proses pembinaan yang disampaikan oleh pengabdi yang berperan sebagai instruktur dan tutor berlangsung dengan kondusif. Materi yang dirancang sedemikian rupa oleh pengabdi dapat dimengerti, dicerna dan dipahami dengan baik oleh peserta. Hal tersebut terbukti dari antusias peserta yang mengikuti pelatihan dengan aktiv berkomunikasi dengan pembicara, sehingga pembinaan terlaksana dengan baik dan interaktif.

Kata Kunci: Pembinaan Pembuatan Media, Power Point
\end{abstract}

\begin{abstract}
Teachers are the drivers of education, in the digital era teachers are required to renew learning by utilizing existing technology with the aim of not lagging behind the times. The facts in the field show that conditions are of concern, the use of technology is still not optimal. This is due to the lack of facilities that support the development of learning technology and also the human resources that control the technology are also minimal. This training aims to provide training by presenting some material related to the development of interactive learning media, namely Microsoft Power Point so that the implementation of SKI learning at Rawabening MI schools does not seem monotonous so as to increase interest and quality of learning among students. The coaching process delivered by the servants who acted as instructors and tutors took place conducively. Material designed in such a way by servants can be understood, understood and well understood by the participants. This was evident from the enthusiasm of the participants who participated in the training actively communicating with the speaker, so that the training was carried out well and interactively.
\end{abstract}

Keywords: Media Making Development, Power Point

\section{PENDAHULUAN}

Guru adalah sebuah profesi mulia karena di tangan merekalah masa depan bangsa ini 
ditentukan. Dalam melaksanakan kewajiban terpenting dari seorang guru yaitu mengajar maka guru perlu adanya suatu media pembelajaran. Media pembelajaran merupakan salah satu alat bantu seorang guru dalam memberikan pemahaman kepada siswanya.

Media sebagai segala sesuatu yang dapat digunakan untuk menyalurkan pesan dan pengirim pesan kepada penerima pesan, sehingga dapat merangsang panca indera, perasaan, perhatian, dan minat serta perhatian siswa sedemikian rupa, sehingga proses belajar mengajar berlangsung dengan efektif dan efisien sesuai dengan yang diharapkan (Sadiman,dkk., 2006:6). Pemakaian media dalam pembelajaran sangat membantu para guru mengajar dalam menyampaikan pesan pembelajaran serta lebih cepat dan lebih mudah di tangkap oleh para siswa. Media memiliki kekuatan yang positif dan sinergi yang mampu merubah sikap dan tingkah laku siswa kearah perubahan yang kreatif dan dinamis. (Arsyad, 2003:37). Penjelasan diatas dapat disimpulkan bahwasanya peran media sangat dibutuhkan dalam pembelajaran dimana perkembangannya saat ini media bukan lagi dipandang sekedar alat bantu tetapi merupakan bagian terpenting dalam sistem pendidikan dan pengajaran.

Perkembangan ilmu pengetahuan dan teknologi semakin mendorong upaya-upaya pembaharuan dalam pemanfaatan hasil-hasil teknologi dalam proses belajar. Media yang dapat menunjang pembelajaran diantaranya adalah media komputer. Salah satu program yang digunakan adalah dengan program Microsoft PowerPoint. Aplikasi ini dapat digunakan untuk membuat maupun menyampaikan materi. (Nasution, 1982:115).

Microsoft PowerPoint menyediakan fasilitas, suara, gambar dan hyperlink, selain itu dilengkapi dengan animasi yang bukan hanya berlaku pada teks saja tetapi juga pada gambar, garis dan sebagainya. Sehingga membuat tampilan pembelajaran menjadi lebih bervariasi, penyajian materi pelajaran dapat sesuai dengan "dunia nyata" siswa.

Microsoft PowerPoint merupakan salah satu program berbasis multi media yang dirancang khusus untuk digunakan sebagai alat presentasi adalah berbagai kemampuan pengelola teks, warna, dan gambar, serta animasi-animasi yang bisa diolah sendiri sesuai kreativitas penggunaannya. Dan banyak manfaat yang dimiliki oleh Microsoft PowerPoint yang telah di paparkan di atas. (Dahria \& Santoso, 2009:252).

Sejarah kebudayaan Islam (SKI) merupakan mata pelajaran Pendidikan Agama Islam (PAI) di madrasah. Aspek SKI menekankan pada kemampuan mengambil ibrahdari peristiwa-peristiwa bersejarah (Islam), meneladani tokoh-tokoh berprestasi, dan mengaitkan fenomena sosial, budaya, politik, ekonomi, iptek, dan seni, dan lain-lain untuk mengembangkan kebudayaan dan peradaban islam. (Hanafi. 2009).

Pentingnya mempelajari SKI salah satunya adalah dapat membangun kesadaran peserta didik tentang pentingnya mempelajari landasan ajaran, nilai-nilai dan norma-norma islam yang telah dibangun oleh Rasulullah SAW dalam rangka mengembangkan kebudayaan dan peradaban Islam. Salah satu penyebab rendahnya prestasi siswa dalam belajar SKI adalah karena terlalu banyak materi yang di ajarkan kebanyakan menggunakan metode ceramah dan siswa menjadi kurang bersemangat dalam menerima pelajaran kalau tidak ada varian metode. Kebanyakan aktivitas siswa hanya mendengar dan mencatat dan tidak mendapatkan kesempatan untuk berpikir lebih dalam (Muflihah \& Maksum, 2016).

Guru dituntut dapat mengembangkan keterampilan membuat media pembelajaran karena metode dan media pembelajaran yang digunakan oleh guru sangat berpengaruh terhadap hasil proses belajar mengajar. Tetapi untuk membuat media tersebut dibutuhkan kemampuan dan pengetahuan, dimana tidak setiap guru mempunyai kemampuan untuk itu. oleh karena itu perlu adanya pelatihan pembuatan media pembelajaran menggunakan Microsoft Power Point untuk para guru Madrasah Ibtidaiyah Rawa Bening.

Berdasarkan penjabaran latar belakang di atas diambil kesimpulan bahwa penting untuk meningkatkan kemampuan guru dalam pemanfaatan media Microsoft Power Point guna mengikuti perkembangan iptek dan juga sebagai alternatif pembelajaran agar tidak monoton dan terkesan membosankan. Dengan demikian penulis tertarik mengadakan pengabdian masyarakat di suatu 
lembaga pendidikan yaitu MI NU Rawabening dalam upaya meningkatkan kemampuan guru dalam pemanfaatan media Microsoft Power Point pada Pelajaran SKI di MI NU Rawabening.

\section{SOLUSI METODE}

Solusi dari pelaksanaan pengabdian kepada masyarakat yakni dengan cara memberikan tutorial atau bimbingan di lokasi pengabdian yang telah dipilih tempatnya terlebih dahulu.Memberikan materi bagaimana membuat Microsoft Power Point dengan menggunakan modul yang telah dipersiapkan oleh team pengabdi kepada guru-guru di MI NU Rawabening.

Pencapaiaan target pada program pengabdian kepada masyarakat "Upaya meningkatkan kemampuan guru dalam pemanfaatan media Microsoft Power Point pada Pelajaran SKI di MI NU Rawabening" yang dilaksanakan oleh Dosen Jurusan Pendidikan Guru Madrasah Ibtidaiyah adalah:

1. Supaya Guru MI dapat terbantu dalam membuat media Power Point.

2. Memanfaatkan materi yang kami buat bertujuan untuk penunjang agar guru mudah memahami dan membuat medianya sendiri.

3. Kegiatan ini dilakukan agar guru terbantu dalam proses kegiatan belajar mengajar (KBM).

Luaran yang dicapai dalam Program Pengabdian kepada masyarakat "Upaya meningkatkan kemampuan guru dalam pemanfaatan media Microsoft Power Point pada Pelajaran SKI di MI NU Rawabening" oleh Dosen Jurusan Pendidikan Guru Madrasah Ibtidaiyah adalah:

1. Meningkatkan kemampuan guru bidang Study SKI dalam menyajikan dan mempresentasikan di depan kelas melalui media Microsoft Power Point.

2. Terciptanya pembelajaran yang efektif dan inovatif agar siswa bersemangat dalam belajar.

3. Terbinanya pembelajaran yang tidak monoton dan dikemas dalam bentuk yang lebih menarik dalam proses pembelajaran SKI.

4. Menumbuhkan motivasi para peserta didik untuk mempelajari pelajaran SKI dengan penyampaian menggunakan media yang menarik.

\section{HASIL DAN DISKUSI}

Kegiatan pengabdian kepada masyarakat yang dilakukan team yakni dengan cara mengadakan wawancara, pemberian tutorial atau bimbingan, praktik langsung, mengadakan kegiatan tanya jawab dan pemberian penilaian berdasarkan pengamatan langsung selama kegiatan Pengabdian. Kegiatan pengabdian dilaksanakan di Madrasah Ibtidaiyah NU Rawabening, Kecamatan Buay Madang Kabupaten OKU Timur. Kegiatan pengabdian kepada masyarakat yang telah berlangsung menunjukan hasil sebagai berikut:

1. Meningkatkan kemampuan guru bidang Study SKI dalam menyajikan dan mempresentasikan di depan kelas melalui media Microsoft Power Point.

2. Membuat pembelajaran yang efektif dan inovatif agar siswa bersemangat dalam belajar.

3. Menciptakan pembelajaran yang tidak monoton dan dikemas dalam bentuk yang lebih menarik dalam proses pembelajaran SKI.

Menumbuhkan motivasi para peserta didik untuk mempelajari pelajaran SKI dengan penyampaian menggunakan media yang menarik. Adapun faktor pendukung dan penghambat dalam pelaksanaan pengabdian pada masyarakat ini. Ada beberapa faktor yang mendukung terlaksananya kegiatan pengabdian pada masyarakat ini adalah besarnya minat dan antusiasme siswa siswi selama kegiatan, sehingga kegiatan berlangsung dengan lancar dan efektif. Sedangkan faktor penghambatnya adalah keterbatasan waktu pada pelaksanaan pengabdian tersebut yakni praktik dalam kelas dengan waktu yang telah ditentukan dari sekolah.

\section{PEMBAHASAN}

Secara garis besar cakupan hasil dari kegiatan pengabdian ini adalah sebagai berikut:

1. Tujuan pengabdian 
2. Target atau Sasaran Pengabdian

3. Kemampuan guru membuat Power Point

Evalusi pelaksanaan kegiatan pembinaan penggunaan media pembelajaran Microsof Power Point dinilai berdasarkan hasil tugas praktik para peserta yang mengikuti pelatihan. Penilaiaan telah menggambarkan keberhasilan materi yang disajikan tim pengabdi.

Berdasarkan pembinaan yang telah dilaksanakan secara umum peserta telah memahami dasardasar penggunaan program Power Point dan telah mampu menerapkannya kedalam bentuk pembuatan media.Teknik evaluasi kegiatan dilakukan dengan cara observasi selama proses kegiatan pembinaan berlangsung. Dengan cara melihat bagaimana kulaitas karya yang dibuat pada saat praktik pembuatan media pembelajaran dengan Power Point. Kemudian melakukan wawancara dengan memberikan pertanyaan-pertanyaaan terkait pelaksanaan kegiatan baik secara individu ataupun kelompok.

\section{SIMPULAN}

Berdasarkan hasil pembinaan dan pelatihan penggunaan media Microsoft Power Point sebagai kegiatan pengabdian masyarakat dapat diambil kesimpulan sebagai berikut:

1. Pelatihan dengan beberapa sajian materi sebagai upaya peningkatan kualitas pembelajaran dengan memberikan pengetahuan mengenai pemanfaatan media power Point sebagai media untuk membuat media pembelajaran yang interaktif.

2. Materi yang disajikan oleh pengabdi dapat dipahami, dicerna dan diterima dengan baik.

3. Kegiatan berlangsung lancar, sesuai harapan dan tepat waktu.

\section{UCAPAN TERIMAKASIH}

Terima kasih yang tak terhingga kepada Ketua STKIP Nurul Huda Sukaraja dan Ketua LPPM STKIP Nurul Huda Sukaraja yang telah memberikan kesempatan kepada kami dalam melaksanakan pengabdian dengan menerbitkan nomor kontrak pengabdian 017/STKIP-NH/LPPM/XI/2018, sebagai salah satu bentuk Tri Darma Perguruan Tinggi di STKIP Nurul Huda Sukaraja, terima kasih juga kepada kepala sekolah Mi NU Rawabening serta seluruh dewan guru yang telah mengikuti pembinaan sehingga terlaksananya kegiatan pengabdian serta memberikan izin kepada kami melaksanakan kegiatan pengabdian di MI NU Rawabening dan kepada semua dosen di lingkungan STKIP Nurul Huda terima kasih atas support dan bantuan moril sehingga pengabdian ini bisa berjalan dengan baik dan lancar.

\section{DAFTAR PUSTAKA}

Arsyad, A. (2003). Media Pembelajaran. Jakarta: PT Raja Grafindo Persada.

Muflihah, A., \& Maksum, K. (2016). Penerapan Metode Scramble untuk Meningkatkan Prestasi

Belajar SKI Kelas V MI AI-Iman Sorogenen. LITERASI (Jurnal IImu Pendidikan), 6(1), 61-75.

Dahria, M., \& Santoso, I. (2009). Manfaat Powerpoin Dalam Presentasi Makalah. LPPM-STMIK Triguna Darma. 6(1).

Hanafi, M. (2009). Pembelajaran Sejarah Kebudaan Islam. Bandung: direktorat Jenderal Pendidikan Islam Kementerian Agama RI

Nasution. (1982). Teknologi Pendidikan. Cetakan Pertama.

Sadiman. (2006). Media Pembelajaran. Jakarta: PT Raja Grafindo Persada 